tốt. Độ nhạy: 100\%; độ đặc hiệu: 94,8\% ; độ chính xác: $93,6 \%$. Nên áp dụng thường quy kỹ thuật chọc hút bằng kim nhỏ (FNA) dưới hướng dẫn của siêu âm trong chẩn đoán u tuyến mang tai. Vì kỹ thuật này giá thành khá rẻ, ít xâm lấn, ít gây biến chứng, có thể linh hoạt làm tại phòng khám và có giá trị cao để chẩn đoán tế bào học của khối u, thông qua đó có thể lâp ra kế hoach điều trị, bảo tồn được dây thần kinh VII và tiên lượng được các biến chứng. Giải phẫu bệnh lý u tuyến mang tai vẫn là tiêu chuẩn vàng trong chẩn đoán xác định bản chất u tuyến mang tai.

\section{TÀl LIẸU THAM KHẢO}

1. Eric R. Carlson Robert A. Ord (2016), "Tumors of the Parotid Gland"Salivary Gland Pathology: Diagnosis and Management, 2nd Edition, Jonh Wiley \& Sons, Inc, Canada, pp. 233-259.

2. Almeslet A. S (2020), "Pleomorphic Adenoma: A Systematic Review", Int J Clin Pediatr Dent. 13(3), pp. 284-287.

3. Ord R A Carlson E R (2016), "Pediatric Salivary Gland Malignancies", Oral Maxillofac Surg Clin North Am. 28(1), pp. 83-9.

4. Đinh Xuân Thành; (2010), Nghiên cứu chẩn đoán và điều trị u tuyên nước bot mang tai, Luận án Tiến sỹ, Trường Đại học Y Hà Nội.

5. Chauhan N Shah j A (2019), "Parotid Gland Tumours: Our Experience", Indian J Otolaryngol Head Neck Surg. 71(3), pp. 378-382.

6. Dhanani R Iftikhar H (2020), "Role of Fine Needle Aspiration Cytology in the Diagnosis of Parotid Gland Tumors: Analysis of 193 Cases". 24(4), e508-e512.

7. Archondakis S, Roma M Kaladelfou E (2021), "Two-Year Experience of the Implementation of the Milan for Reporting Salivary Gland Cytopathology at a Private Medical Laboratory", Head Neck Pathol.

8. Dhanani R (2020), "Role of Fine Needle Aspiration Cytology in the Diagnosis of Parotid Gland Tumors: Analysis of 193 Cases". 24(4), e508-e512.

\title{
HIÊ̂U QUẢ TẠO NGÀ SỬA CHỮA CỦA XI MĂNG CALCIUM SILICATE (BIODENTINETM) TRONG ỨNG DỤNG CHE TUỶ GIÁN TIẾP
}

Trần Xuân Vĩnh*

\section{TÓM TẮT}

Mục tiêu: Đánh giá hiệu tạo ngà sửa chữa của xi măng calcium silicate (Biodentine ${ }^{\mathrm{TM}}$ ) trong ứng dụng lâm sàng che tuỷ gián tiếp. Đối tượng và phương pháp nghiên cứu: Bệnh nhân nữ 20 tuổi đau khi nhai hoặc uống nước nóng/lạnh vùng răng số 37. Khám lâm sàng ghi nhận răng 37 có tổn thương sâu răng lớn; răng đáp ứng với thử điện/lạnh. Dựa trên khám lâm sàng và hình ảnh $X$ quang, răng được chẩn đoán là viêm tủy có hồi phục. Răng được gây tê trước đă̆t đê cao su để cô lập răng. Mô ngà sẩu được loại bỏ bằng kỹ thuật loại bó ngà sâu chọn lọc một bước với mũi khoan tròn vô trùng và tay khoan cao tốc dưới nguồn nước. Xoang trám được khử trùng bằng gạc vô trùng thấm $\mathrm{NaOCl} 2,5 \%$ trước khi trám với Biodentine $^{T M}$ (Septodont, Saint Maur des Fosses Cedex, Pháp). Sau 1 tháng răng được trám kết thúc với resin composite (3M ESPE, St Paul, MN, USA). Đánh giá lâm sàng và $X$ quang được thực hiện sau 6 tháng và 1 năm. Kêt quả: Bệnh nhân có cơn đau nhe ngay sau khi điều trị, nhưng hết nhanh chóng. Sau 1 tháng, 6 tháng và 1 năm, bệnh nhân không có các triệu chứng bất thường, ăn nhai tốt. Răng đáp ứng với thử nghiệm điện và lạnh. Hình ảnh $X$ quang quanh chóp cho thấy có sự hình thành ngà sửa chữa ngay

*Đại Học Y Dược Tp. Hồ Chí Minh

Chịu trách nhiệm chính: Trân Xuân Vĩnh

Email: vinhdentist@yahoo.com

Ngày nhận bài: 7.5.2021

Ngày phản biện khoa học: 25.6.2021

Ngày duyệt bài: 6.7.2021 bên dưới vùng che tuỷ sau 6 tháng, vùng quanh chóp và khoảng dây chằng nha chu bình thường sau 1 năm. Kết luận: Biodentine ${ }^{\mathrm{TM}}$ có thể là một lựa chọn tối ưu cho ứng dụng lâm sàng che tuỷ giản tiếp và có khả năng kích thích tạo ngà sửa chữa.

Tư khoá: Che tuỷ gián tiếp, viêm tuỷ có hồi phục, Biodentine $^{T M}$, xi măng calcium silicate.

\section{SUMMARY}

THE EFFECT OF CALCIUM SILICATE CEMENT (BIODENTINETM) ON REPARATIVE DENTINOGENESIS FOLLOWING INDIRECT DIRECT PULP CAPPING

Objective: Evaluation of the effect of calcium silicate cement (Biodentine ${ }^{\mathrm{TM}}$ ) on reparative dentinogenesis following indirect pulp capping. Methods: A 20-year-old female patient presented the pain in tooth number 37 when eating or cold/hot drinking, occurring several times over the previous one month. Based on the clinical and radiographic examinations, tooth was diagnosed with reversible pulpitis. The tooth was anaesthetized before placement rubber dam for isolation. Decayed tissues were removed using a sterilized high-speed round bur under water coolant. The cavity was disinfected by a sterile cotton pellet soaked in $2,5 \%$ sodium hypochlorite before capping with Biodentine ${ }^{T M}$. The tooth was finally restored with resin composite after one month. Clinical and radiographic evaluation was completed at 6 months and 1 year postoperatively. Results: The patient reported the mild pain occurred for the first post treatment day, but pain was soon alleviated. After 6 months and one year, the patient 
had no complaint about the tooth, positive responses to cold and electric pulp tests, and periapical radiographs showed the formation of reparative dentin underlying the cavity, no periapical lesion. Conclusions: Biodentine ${ }^{T M}$ can be an optimal option for indirect pulp capping and is able to induce the reparative dentinogenesis.

Tư khoá: indirect pulp capping, reversible pulpitis Biodentine $^{\mathrm{TM}}$, calcium silicate based cement.

\section{I. ĐĂT VẤN ĐỀ}

Che tuỷ trực tiếp và gián tiếp được sử dụng trong nhiều năm để bảo tồn sự sống của phức hợp tủy răng và kích thích tế bào tủy hình thành mô cứng khoáng hoá (ngà răng phản ứng/ngà sửa chữa). Che tuỷ trực tiếp được chỉ định khi tủy răng bị lộ do sâu răng, chấn thương, hoặc do quá trình sửa soạn, loại bỏ ngà sâu. Che tuỷ gián tiếp thường được sử dụng trong trường hợp sâu ngà sâu gần sát với tuỷ nhưng chưa lộ tuỵ. Tủy răng có khả năng sửa chữa, tùy thuộc vào mức độ tổn thương và tình trạng viêm tủy. Trong trường hợp một sang thương sâu răng tiến triển tương đổi chậm, các phân tử ban đầu gần với mô tuỷ có thể kích thích sự tái tạo ngà răng. Ngà răng có thể được tái tạo nhờ nguyên bào ngà, nằm ở ngoại vi của tủy, bên dưới vùng sang thương và chịu trách nhiệm duy nhất trong việc tổng hợp ngà răng. Chúng có thể điều hoà các hoạt động tiết ngà và tạo ra một lớp ngà sửa chữa dày, giúp bảo vệ mổ tuỷ.

Việc điều trị các tổn thương sâu ngà sâu là một thách thức lớn, đặc biệt khi sang thương gần mô tuỷ, tăng nguy cơ làm lộ tuỷ. Điêu trị che tuỷ gián tiếp là thủ thuật để lại lớp ngà sát tuỷ, nhưng tránh làm lộ tuỷ. Phần ngà răng bên dưới này được che bởi một vật liệu tương hợp sinh học, tạo ra sự bám dính, bít kín sinh học [1]. Che tuỷ gián tiếp là một phương thức điểu trị duy trì sự sống của tuỷ bằng cách tạo điều kiện thuận lợi cho sự lành thương và sửa chữa phức hợp ngà tuỷ.

Trước đây, calcium hydroxide là vật liệu che tuỷ được xem là chuẩn vàng. Tuy nhiển, vật liệu này có thể bị phân hủy theo thời gian và không bám dính tốt với ngà răng, đồng thời có nhiều khiếm khuyết bên trong cầu ngà sửa chữa được hình thành. Những đặc tính này có thể cho phép tạo vi kẽ và là nguyền nhân thất bại trong điều trị bảo tồn tuỷ sống. Sự ra đời các vật liệu calcium silicate hoạt tính sinh học như MTA (ProRoot MTA, Dentsply, USA) và Biodentine ${ }^{T M}$ (Septodont, Saint Maur des Fosses, Pháp) mang lại nhiều ưu điểm hơn calcium hydroxide. Biodentine $^{T M}$ được cho là có thể sử dụng làm vật liệu thay thế ngà bên cạnh các chỉ định trong điêu trị nội nha tương tự MTA. Xi măng trám này được cải thiện thời gian đông cứng, thao tác và đặc tính cơ học khi so sánh với xi măng MTA [2]. Biodentine ${ }^{\mathrm{TM}}$ có thể được sử dụng như vật liệu che tuỷ gián tiếp và trám tạm trong thời gian ít nhất 6 tháng [3]. Nghiên cứu in vitro cho thây Biodentine $^{\mathrm{TM}}$ có khả năng tương tác sinh học với ngà răng, tạo lớp mô giao diện vững chắc, hạn chế tạo vi kẽ [4].

Khả năng tạo ngà sửa chữa của Biodentine ${ }^{\mathrm{TM}}$ qua lớp ngà còn lại trong ứng dụng che tuỷ gián tiếp vẩn ít được đề câp, đặc biệt là các báo cáo lâm sàng. Mục đích của nghiên cứu này là đánh giá hiệu quả tạo ngà sửa chữa của Biodentine ${ }^{\mathrm{TM}}$ trong ứng dựng lâm sàng che tuỷ gián tiếp.

\section{II. ĐỐI TƯỢNG VÀ PHƯƠNG PHÁP NGHIÊN CỨU}

Bệnh nhân nữ 20 tuổi, đau khi ăn nhai hoăc uống nước nóng/lạnh vùng răng số 37 , bắt đầu từ một tháng trước. Khám lâm sàng ghi nhận răng 37 có tổn thương sâu răng lớn, răng đáp ứng với thử tuỷ điện/lạnh. Hình ảnh $X$ quang quanh chóp cho thấy sâu ngà sâu gần tuỷ, vùng quanh chóp và khoảng dây chằng nha chu bình thường (Hình $1 A)$. Dựa trên dấu hiệu khám lâm sàng và hình ảnh $X$ quang, răng được chẩn đoán là viêm tủy có hồi phục. Bệnh nhân được thông báo kế hoạch điêu trị che tuỷ gián tiếp với Biodentine ${ }^{T \dot{M}}$.
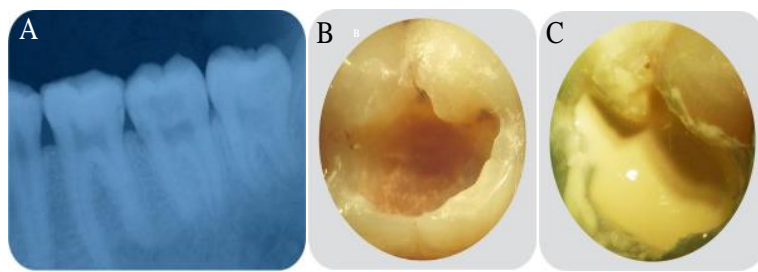

Hình 1. A. trước điều trị; B. sưa soạn xoang trám; $\boldsymbol{C}$. trám Biodentine ${ }^{T M}$

Răng được gây tê với Lidocaine hydrochloride $2 \%$ và Epinephrine 1: 100.000 (Septodont, Saint-Maur-des-Fosses Cedex, Pháp) trước khi đặt đê cao su để cô lập răng. Răng và vùng sâu răng được sát trùng bằng gạc thấm $\mathrm{NaOCl} 5 \%$. Mô ngà sâu được loại bỏ cho đến khi phần ngà còn lại không còn mô viêm, rắn chắc (Hình $1 \mathrm{~B}$ ), bằng kỹ thuật loại bỏ ngà sâu chọn lọc một bước với mũi khoan tròn vô trùng và tay khoan cao tốc dưới nguồn nước. Sau đó, xoang được khử trùng bằng gạc vô trùng thấm trong $\mathrm{NaOCl} 2,5 \%$ trước khi trám bằng Biodentine ${ }^{\mathrm{TM}}$ (Septodont, Saint Maur des Fosses Cedex, Pháp). Xoang trám cũng được lấp đầy bằng Biodentine ${ }^{\mathrm{TM}}$. Trong trường hợp này, Biodentine ${ }^{\mathrm{TM}}$ được xem như là 
vật liệu trám tạm (Hình 1 C). Bệnh nhân được hẹn lại sau một tháng trừ khi có cơn đau tiến triển xảy ra. Trong lần hẹn tiếp theo, khối Biodentine ${ }^{\mathrm{TM}}$ phía trên được loại bỏ, để lại một lớp dày khoảng $3 \mathrm{~mm}$ bên dưới, trám kết thúc với resin composite (3M ESPE, St Paul, MN, USA). Đánh giá lâm sàng và $X$ quang được thực hiện sau sau 6 tháng và 1 năm.

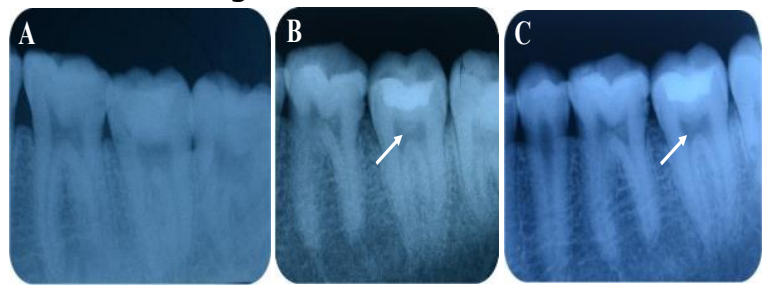

Hình 2. A. sau khi trám Biodentine ${ }^{T M}$; B. sau 6 tháng; C. sau 12 tháng

\section{KẾT QUẢ NGHIÊN CỨU}

Ngày đầu tiên sau điều trị, bệnh nhân xuất hiện cơn đau nhẹ, nhưng cơn đau hết một cách nhanh chóng. Theo dõi sau 1 tháng, 6 tháng và 1 năm, bệnh nhân không có các triệu chứng bất thường, ăn nhai tốt. Răng đáp ứng với thử nhiệm điện và lạnh. Hình ảnh $X$ quang quanh chóp sau 6 tháng và 1 năm cho thấy có sự hình thành ngà sửa chữa (mũi tên, Hình $2 \mathrm{~B}, \mathrm{C}$ ) ngay bên dưới vùng che tuỷ, vùng quanh chóp và khoảng dây chẳng nha chu bình thường.

\section{BÀN LUÂN}

Sư tác động lên đông học của phức hợp ngà tuỷ trong quá trình trám và đáp ứng tuỷ với vật liệu che tuỷ đã thu hút sự quan tâm của nhiều nhà nghiên cứu và lâm sàng. Việc sửa soạn xoang trám và qui trình điều trị được ghi nhận là nguồn gốc gây tổn thương mô tuỷ. Mức độ viêm của tuỷ răng bên dưới xoang trám phụ thuộc vào bề dày lớp ngà còn lại và sự hình thành vi kẽ xung quanh vật liệu trám [5]. Số lượng nguyên bào ngà sống sót sau chấn thương do sửa soạn xoang trám, tiến triển sâu răng, quá trình điều trị và sự hình thành ngà sửa chữa có liên quan với bề dày lớp ngà còn lại.

Trong che tuỷ gián tiếp, đặc tích sinh học, khả năng bám dính giúp hạn chế tạo vi kẽ của vật liệu trám là những yểu tố hểt sức quan trọng, đảm bảo sự thành công lâu dài của điều trị bảo tồn sự sống của tuỷ. Biodentine ${ }^{\mathrm{TM}}$ là vật liệu có tính kiềm và phóng thích ion $\mathrm{Ca}^{2+}$ và $\mathrm{OH}^{-}$ trong quá trình đông cứng, tạo ra môi trường lành thương tối ưu. Các đặc tính sinh học của Biodentine $^{T M}$ liên quan đến sửa chữa mô ngà-tuỷ và biệt hóa tế bào dạng nguyên bào ngà đã được đề cập trong nhiều báo cáo trong ứng dụng che tuỷ trực tiếp $[6,7]$.

Nghiên cứu của chúng tôi cho thây sau 6 tháng đã có sự hình thành ngà sửa chữa ngay bên dưới xoang trám. Chính lớp ngà sửa chữa này làm tăng khoảng cách giữa vật liệu trám và mô tuỷ bên dưới và là hàng rào bảo vệ sự sống của mô tuỷ. Ion $\mathrm{OH}^{-}$phóng thích trong quá trình đông cứng của vật liệu tạo môi trường kiềm có tính diệt khuẩn, hoà tan khuôn ngà của lớp ngà còn lại làm phóng thích các phân tử sinh học. Các phần tử sinh học này cùng với ion $\mathrm{Ca}^{2+}$ từ vật liệu di chuyển qua ống ngà kích thích lớp nguyển bào ngà tạo ngà sửa chữa [2].

Sau 1 năm theo dôi, răng không có dấu hiêu bất thường. Bênh nhân ăn nhai tốt và răng đáp ứng với thử điện/lạnh. Hình ảnh $X$ quang cho thấy mô quanh chóp bình thường. Biodentine ${ }^{\mathrm{TM}}$ được chứng minh là có khả năng kích thích lớp nguyên bào ngà còn sống sót bên dưới ngà sâu, tạo ngà sửa chữa. Khả năng bám của vật liệu che tuỷ và vật liêu trám kết thúc bên trên đóng vai trò quan trong cho sự thành công lâu dài. Biodentine ${ }^{T M}$ khi tiếp xúc với ngà răng tạo "cấu trúc đuôi" dọc giao diện vật liệu/ngà răng được gọi là "vùng xâm nhập khoáng hoá". Lớp cẩu trúc ở giao diện này giúp vật liệu bám tính tốt vào mô răng, đề kháng với sư hình thành vi kẽ, hạn chế sâu răng tái phát [8]. So với calcium hydroxide, Biodentine ${ }^{T M}$ có đặc tính cơ lý nổi trội hơn, khả năng bám dính vào mô răng cao, ít hoà tan theo thời gian. Tran và cs (2012) đã chứng minh rằng phẩn trăm cấu trúc rỗng bên trong câuu ngà sữa chữa hình thành bởi Biodentine ${ }^{T M}$ sau 14 và 30 ngày ít hơn so với nhóm che tuỷ với calcium hydroxide. Dựa trên đắc tính sinh học của xi măng Porland, vật liệu calcium silicate-Biodentine ${ }^{\mathrm{TM}}$ có thành phần bột chính là tricalcium silicate, calcium carbonate, zirconium oxide. Phần lỏng chứa nước, calcium chloride và polycarboxylate biến đổi. Nowicka và cs (2013) cho rằng Biodentine ${ }^{\mathrm{TM}}$ có thể là lựa cho thay thế MTA trong ứng dụng che tuỷ chính vì đăc tính sinh học tương tự MTA. Biodentine ${ }^{\mathrm{TM}}$ có đặc tính cơ lý được cải tiến so với MTA, thời gian đông cứng ngẳn (khoảng 12 phút), dễ thao tác và không gây đổi màu răng. Biodentine ${ }^{T M}$ có thể sử dụng đồng thời như vật liêu trám tạm sau khi che tuỷ, mà không cần sử dụng GIC trám tạm bên trên như trong qui trình che tuỷ với MTA.

Mục tiêu cuối cùng của thủ thuật che tuỷ là kiểm soát vi khuẩn, ngăn chặn quá trình sâu răng tái phát, kích thích các tế bào tủy răng tạo ngà mới. Đặc biệt, vật liệu che tuỷ phải có khả 
năng tạo bám dính sinh học bền vững giúp bảo vệ phức hợp tuỷ từ sự xâm nhập vi khuẩn và các tác nhân độc hại.

\section{KẾT LUÂN}

Với sự phát triển của xi măng calcium silicate có nhiều ưu điểm về đặc tính sinh học và cơ lý,

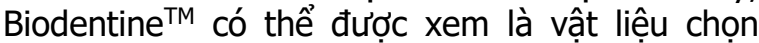
lựa tối ưu trong ứng dụng che tuỷ gián tiếp. Các nghiên cứu lâm sàng với số lượng ca lớn, theo dõi lâu dài là cần thiết.

\section{TÀl LIẸU THAM KHẢO}

1. Dhar V, Marghalani AA, Crystal Yo, et al. Use of vital pulp therapies in primary teeth with deep caries lesions. Pediatr Dent 2017;39(5):E146-E159.

2. Pradelle-Plasse. $N$, Tran $X V$, Colon $P$, Laurent P, Aubut V, About I, Goldberg M. Emerging trends in (bio) material research. Biocompatibility or Cytotoxic Effects of Dental Composites, 1st ed.; Coxmoor Publishing Company: Oxford, UK, 2009; pp.181-203

3. Koubi G, Colon P, Franquin JC, Hartmann A,
Gilles R, Faure MO, Lambert G. Clinical evaluation of the performance and safety of a new dentine substitute, Biodentine, in the restoration of posterior teeth - a prospective study. Clin Oral Invest 2013; 17: 243-249.

4. Kim JR, Nosrat A, Fouad AF. Interfacial characteristics of Biodentine and MTA with dentine in simulated body fluid. J Dent 2015;43:241-7.

5. About I, Murray PE, Franquin JC, et al. The effect of cavity restoration variables on odontoblast cell numbers and dental repair. J Dent 2001;29:109-17.

6. Nowicka A, Lipski M, Parafiniuk $M$, et al. Response of human dental pulp capped with Biodentine and mineral trioxide aggregate. J Endod 2013;39:743-7.

7. Tran XV, Gorin C, Willig C, Baroukh B, Pellat B, Decup F, Opsahl Vital $S_{\text {, Chaussain } C_{\text {, }}}$ Boukpessi T. Effect of a stepicalcium-silicatebased restorative cement on pulp repair. J Dent Res. 2012, 91, 1166-1171. 91:454-9.

8. Atmeh AR, Chong EZ, Richard G, Festy F, Watson TF; Dentin cement interfacial interaction: calcium silicates and polyalkenoates. Journal of Dental Research 2012; 91:454-9.

\title{
KHẢO SÁT MỐI LIÊN QUAN GIỮA ĐĂC ĐIỂM HÌNH ẢNH CộNG HƯỞNG TỪ VÀ MÔ BỆNH HỌC CỦA U MÀNG NÃO
}

\author{
Nguyễn Hữu Hoạt ${ }^{1}$, Đặng Đức Cảnh ${ }^{2}$, \\ Ngô Tuấn Minh ${ }^{2}$, Nguyễn Việt Dũng ${ }^{2}$, Nguyê̂n Xuân Khái ${ }^{3}$
}

\section{TÓM TẮT}

Muc đích: khảo sát mối liên quan giữa đặc điểm hình ảnh cộng hưởng từ (CHT) và tính chất lành tính/ác tính của u màng não (UMN). Đối tượng và phương pháp nghiên cứu: mô tả cắt ngang, trện 73 bênh nhân được chẩn đoán UMN, đã được phẩu thuật và có kết quả giải phẫu bệnh là UMN tại Bệnh viện Việt Đức và Bệnh viện Quân y 103 tử tháng $10 / 2020$ đến tháng $03 / 2021$. Kết quả: $56 / 73$ trường hợp là UMN lành tính, chiếm tỷ lệ 76,7\%. UMN không điển hình và ác tính chiếm tỷ lệ 23,3\%. 16/17 khối UMN độ II có hạn chế khuếch tán trên ảnh DWI và ADC, chiếm tỷ lệ $94,1 \%$, trong khi tỷ lệ này ở nhóm UMN độ I là $33,9 \%$. Sư khác biệt này là có ý nghĩa thống kê, $p<0,05$. Kết luận: CHT khuếch tán là kỹ thuật có giá trị trong dự đoán tính chất lành tính/ác tính của UMN trước phẫu thuât não,.

Tư khóa: cộng hưởng từ khuếch tán, u màng

${ }^{1}$ Bênh viên Đa khoa Hoàn Mỹ

2Viện Bỏng Quốc gia Lê Hữu Trác

33eệnh viện Quân y 103

Chịu trách nhiệm chính: Nguyễn Xuân Khái

Email: drxuankhai@gmail.com

Ngày nhận bài: 5.5.2021

Ngày phản biện khoa học: 24.6.2021

Ngày duyệt bài: 5.7.2021

\section{SUMMARY}

MAGNETIC RESONANCE IMAGING AND PATHOLOGICAL CORRELATES OF MENINGIOMAS

Objectives: To evaluate characteristics of meningiomas on magnetic resonance imaging in the differential diagnosis of benign and atypical/malignant meningiomas. Subjects and methods: crosssectional description, 73 patients diagnosed with the meningioma, had surgery and pathology results were meningioma at Viet Duc Hospital and 103 Military Hospital from October 2020 to March 2021. Results: $56 / 73$ cases were mostly benign; account for $76.7 \%$. Atypical and malignant meningiomas accounted for $23.3 \%$. Grade II atypical meningiomas had diffusion restriction on DWI, with $16 / 17$ tumors accounting for $94.1 \%$, while this rate in grade I menigiomas was $33.9 \%$. This difference was statistically significant, $p$ $<0.05$. Conclusion: diffusion-weighted was a valuable technique in predicting benign/malignant properties of meningiomas before surgery.

Keywords: diffusion-weighted magnetic resonance imaging, meningiomas.

\section{I. ĐĂT VẤN ĐỀ}

UMN là loại u xuất phát từ lớp màng não bao quanh não hoặc tủy sống, phân lớn là lành tính, là những khối u hay gặp sau u tế bào hình sao. Theo Black, tại Hoa Kỳ, UMN chiếm tỷ lệ khoảng 